
\title{
Research Square \\ Influence of Hydrate Exploitation On Stability of Submarine Slopes
}

\author{
Yapeng Zhao ( $\nabla$ yapeng_sea@163.com ) \\ Qingdao University of Technology \\ Liang Kong \\ Qingdao University of Technology \\ Lele Liu \\ Qingdao Institute of Marine Geology \\ Jiaqi Liu \\ Qingdao University of Technology
}

\section{Research Article}

Keywords: Natural gas hydrate, Decomposition, Landslide, Strength reduction, Submarine slope

Posted Date: November 30th, 2021

DOI: https://doi.org/10.21203/rs.3.rs-1117705/v1

License: (c) (1) This work is licensed under a Creative Commons Attribution 4.0 International License. Read Full License

Version of Record: A version of this preprint was published at Natural Hazards on March 23rd, 2022. See the published version at https://doi.org/10.1007/s11069-022-05321-y. 


\section{Abstract}

The decomposition of natural gas hydrate will reduce the cementation effect of hydrate and produce ultra-static pore pressure, which will change the mechanical characteristics of the reservoir. Eventually, a series of geological disasters could be triggered, of which the submarine landslide is a typical example. In order to analyze the stability of hydrate-bearing submarine slopes and to explore the internal relationship between hydrate decomposition and submarine landslides, a "two-step reduction method" was described in this paper. This method was based on a strength reduction approach, which can be used to assess the effects of the initial geostress balance and hydrate decomposition on substrate strength reduction. This method was used to reveal the essence of hydrate decomposition and then a joint operation mode of multi-well was proposed. The internal relationship between hydrate decomposition and submarine landslides were analyzed in detail. And the development process and mechanism of submarine landslide were deeply discussed. The results showed that hydrate decomposition is a dynamic process of stress release and displacement, where the "stress inhomogeneity" distributed along the slope is transformed into "displacement inhomogeneity". We concluded that hydrate decomposition could trigger a submarine landslide, especially along a sliding surface. The formation of submarine landslide is a gradual development process, and presents the dual characteristics of time and space.

\section{Introduction}

Natural gas hydrate (NGH) is a non-stoichiometric caged crystalline substance formed by natural gas and water molecules under high pressure and low temperature (Englezos, 1993). It is widely distributed in global offshore continental shelf environments and the onshore permafrost zones (Boswell and Collett, 2011). Due to its huge resource reserves, NGH is considered an alternative energy source of great potential for the 21 st century (Thakur, 2010). The exploitation of hydrates has been successfully tested in the Russia, Canada, USA, Japan and China (Boswell et al., 2012; Chand and Minshull, 2004; Kimura et al., 2019; Makogon et al., 2005), in order to assess the technical feasibility of hydrate mining. China successfully tested and produced hydrates in the northern South China Sea in 2017 and 2020 (Li et al., 2018; Sun et al., 2021; Zhu et al., 2021), establishing world records in the process for total gas production and average daily gas production. They demonstrated that muddy silt hydrate resources could be exploited in a safe and controlled manner.

Production methods for hydrate include heating, depressurization, chemical reagent injection, carbon dioxide replacement or a combination of methods (Collett, 2005; Koh et al., 2002; Moridis et al., 2007; Wang et al., 2014). Although the methods are different, the essence of hydrate exploitation is hydrate decomposition (Li et al., 2021; Tupsakhare et al., 2017). However, when the hydrate decomposes, the contribution made by hydrate as an agent of cementation also disappears and ultra-static pore pressure is generated. The strength of the hydrate and hence surrounding strata decreases, which can trigger a submarine landslide or submarine turbidity current and cause wellbore instability and platform overturning (Li et al., 2014; Li and Han, 2021; Liu et al., 2017; Rutqvist et al., 2009; Sultan et al., 2004; Zhang et al., 2021). In addition, one of these geological events may also trigger another, initiating what 
has been called a "disaster chain" (Lu et al., 2019). With the continuous expansion of the scale of an event, long-term and large-scale geological disasters can be induced. A submarine landslide, which is associated with hydrate decomposition, is a typical example.

Terrestrial slope stability has been intensively studied, with the limit equilibrium method and numerical analysis methods widely used to analyze slope stability (Li and Yang, 2019; Liu et al., 2021; Luo et al., 2018; Wang et al., 2019; Zaniboni et al., 2016). At the same time, a series of detailed research methods have been developed based on different considerations. Examples of the latter include the simplified Bishop method (Bishop, 1955; Cheng and Yip, 2007), Janbu method (Tang et al., 2020) and the upper bound method of limit analysis based on plastic mechanics (Zhang et al., 2018). In terms of numerical analysis, the strength reduction method is well-known and has been widely used (Bolla and Paronuzzi, 2020; Wang et al., 2020). In contrast to terrestrial slopes, submarine slopes have a more complex geological environment, but they still have much in common. As a result, research methods similar to those developed for terrestrial slopes can be used for analysis of the submarine slopes. Tan et al. (2021) analyzed the stability of submarine slopes during the exploitation of gas hydrates, within the framework of the limit equilibrium method. Leynaud et al. (2004) used the limit equilibrium and finite element methods to study the static and dynamic (seismic) stabilities of the dipping seabed. Song and co-workers (Song et al., 2019a; Song et al., 2019b) investigated the stability of hydrate-bearing submarine slopes (HBSS) at different gradients using the strength reduction method. Kong et al. (2018) carried out multifactor sensitivity analysis of submarine slopes based on strength reduction method. Zheng et al. (2019) combined limit analysis with strength reduction to discuss the influence of wave pressure on the stability of submarine sensitive clay slopes. Chen et al. (2020) established the finite element model of waveseabed interaction and evaluated the stability of artificial submarine slopes based on strength reduction method.

A relatively limited amount of research has been carried out on the stability of submarine slopes affected by hydrate decomposition. There has been no systematic research on the internal relationship between hydrate decomposition and submarine landslides. In addition, although the stability of HBSS has been explored by some scholars (Elger et al., 2018; Jiang et al., 2015; Kong et al., 2018; Kwon and Cho, 2012; Song et al., 2019a), most of them made qualitative assessments based on the obtained safety factor, while the influence of hydrate decomposition before a landslide was ignored. We propose a "two-step reduction method" which can consider the initial stress balance, hydrate decomposition and strength reduction. The influence of hydrate decomposition on the stability of submarine slopes was comprehensively studied using this method. In this study, the potential effects of hydrate decomposition were revealed and reasonable engineering solutions proposed. The processes and mechanisms associated with submarine landslides were analyzed in detail.

\section{Two-step Reduction Method}

\subsection{Strength reduction method}


The strength reduction method was first proposed by Zienkiewicz (Zienkiewicz et al., 1975). As a method to evaluate slope stability evaluation, it has been widely used by many scholars due to its simplicity and the ease with which it can be understood. The reduced shear strength parameter can be expressed as:

$$
\left\{\begin{array}{c}
c_{\mathrm{m}}=c / F_{\mathrm{r}} \\
\varphi_{\mathrm{m}}=\arctan \left(\tan \varphi / F_{\mathrm{r}}\right)
\end{array}\right.
$$

where $c$ and $\varphi$ are the shear strength that soil can provide; $c_{\mathrm{m}}$ and $\varphi_{\mathrm{m}}$ are the shear strength needed to maintain balance or actually exerted by soil. $F_{\mathrm{r}}$ is the strength reduction factor.

In the finite element analysis, different strength reduction factors $\left(F_{\mathrm{r}}\right)$ are assumed first and then calculated and analyzed according to the reduced strength parameters. During the calculation process, the value of $F_{\mathrm{r}}$ increases continuously until critical failure is reached. The strength reduction factor $\left(F_{\mathrm{r}}\right)$ at critical failure is then the safety factor of slope stability.

\subsection{Two-step reduction method}

When the strength reduction method is used, the initial geostress should be balanced first and then for the strength to be reduced. For most research parameters, such as slopes, they have reached a stable state under long-term geological action. The mechanical parameters of slopes are therefore assumed to remain unchanged for modelling purposes. When carrying out strength reduction, it is only necessary to balance the initial geostress and then carry out strength reduction. However, for some geological parameters that have been affected by recent disturbances (e.g. earthquake, blasting, etc.), their mechanical parameters would have changed to an unknown extent. The following issues therefore need to be taken into consideration in relation to disturbances:

(1) For an unspecified time after a disturbance, the new geostress field would not have stabilized. If new mechanical parameters were given to geological attributes in this post-disturbance transitional stage of stress field evolution, it would obviously be inconsistent with the actual situation when the stress field is in a stable state. This scenario (transitional stage) could not be used to model the impact of hydrate decomposition on slope stability.

(2) According to the different research purposes, what we need may be the analysis of disturbance process or disturbance influence after the balance of initial geostress.

(3) The change of model parameters caused by geological disturbance may be local or global, thereby making the simulation process and interpretation of any results difficult.

If the limitations listed above are taken into account and combined with the strength reduction implementation of ABAQUS, a simple and effective "two-step reduction method" can be used to assess slope stability. The main steps are as follows: 
(1) Firstly, the field variable is added, and then the mechanical parameters that need initial balance are set to correspond to the initial value of the field variable (the initial value of the field variable should be less than 1).

(2) According to the actual situation, the mechanical parameters affected by the disturbance are given to the whole or part of the strata of the geological object, and set to the corresponding field variable value of " 1 ".

(3) Strength reduction is carried out on the basis of the mechanical parameters corresponding to the field variable value " 1 ", and the mechanical parameters corresponding to each field variable value are given.

(4) Establish the first analysis step (initial balance) and adopt the mechanical parameters corresponding to the initial values of field variables.

(5) Establish the second analysis step, and reduce the strength to the field variable value " 1 ".

(6) Establish the third analysis step, and reduce the strength to the final value of the field variable.

When the influence of different degrees of disturbance are analyzed, or the rock stratum in a local area is disturbed, it is only necessary to modify the mechanical parameters corresponding to the variable value " 1 " of the disturbed rock stratum field. The two-step reduction method can be expressed by formula (2):

$$
\left\{\begin{array}{c}
c_{1}=F(c) \\
\varphi_{1}=F(\varphi) \\
c_{\mathrm{m}}=c_{1} / F_{\mathrm{r}} \\
\varphi_{\mathrm{m}}=\arctan \left(\tan \varphi_{1} / F_{\mathrm{r}}\right)
\end{array}\right.
$$

where $c$ and $\varphi$ are the shear strength that undisturbed soil can provide, while $c_{1}$ and $\varphi_{1}$ are the shear strength that the disturbed soil can provide. $F(c)$ and $F(\varphi)$ represent the relationship between undisturbed and disturbed soil shear strength. The values for $F(c)$ and $F(\varphi)$ are determined by the actual situation or research needs. $c_{\mathrm{m}}$ and $\varphi_{\mathrm{m}}$ are the shear strength needed to maintain balance, or the shear force exerted by the soil. $F_{\mathrm{r}}$ is the strength reduction factor.

To sum up, the "two-step reduction method" can be classified as a type of "variable strength stability analysis" that can be used to assess the potential impact of disturbances on slope sediments (e.g. earthquake, blasting, hydrate decomposition, preloading). It is especially suitable for comparative analysis of overall stability, which is accompanied by local strength changes. The main advantages of the "two-step reduction method" are:

(1) Avoidance of repeated geostress balance and mechanical parameter assignment. 
(2) It can be used to assess slope stability for different degrees of disturbance and different disturbance forms (linear and nonlinear).

(3) It can be used to assess the effect small-scale changes in the geostress field on slope stability.

(4) It can be used for a comprehensive analysis of initial stress balance (the first analysis step), the effect of disturbance (the second analysis step) and strength reduction (the third analysis step) through a single ".cae" file containing multiple steps for analysis.

\subsection{Slope instability criteria}

Generally, there are three criteria for slope instability (Masson et al., 2011; Song et al., 2019a):

(1) Formation of a continuous plastic zone (plastic zone penetration).

(2) Sudden change of displacement at the top of a slope.

(3) Calculation stopped due to non-convergence.

In the process of strength reduction, the three criteria show a progressive relationship in time. First, the plastic zone is formed at the bottom of the slope and develops upward, then the plastic zone penetrates, and finally the displacement of the top of the slope changes suddenly. With a further reduction of strength, the plastic zone expands continuously, accompanied by increased displacement and ultimately large-scale instability of the slope. This is represented by non-convergence of the calculation. As long as the consistent criterion is adopted for an actual calculation, the safety factor obtained can be used for qualitative and quantitative analysis. Considering that the first two criteria need to be combined with cloud images for artificial judgment, this paper has used the interruption of calculation due to nonconvergence as the consistent criterion for judging slope instability.

\section{Numerical Model}

\subsection{Applicability of the two-step reduction method}

The focus of this paper was the stability of HBSS. The paper investigated the influence of hydrate decomposition on the stability of submarine slopes exposed to seawater pressure (depth) and gravity. The decomposition of NGH will decrease the mechanical strength of the sediments comprising the hydrate reservoir. Therefore, the key problem to be considered is the change of mechanical properties of hydrate reservoir when the decomposition degree of hydrate is different. When the strength reduction method is used to analyze the slope after hydrate decomposition, the cardinal number " 1 " (the overall mechanical parameters of the macroscopic submarine slope) corresponding to different degrees of decomposition is also different. In addition, the hydrate reservoirs with different degrees of decomposition in the natural environment are in the same state before decomposition (all in equilibrium state under overlying seawater pressure and self-weight stress). Therefore, it is impossible to simply give 
the mechanical parameters after hydrate decomposition to the reservoir, and then carry out initial balance and strength reduction. By using the approach described above, the stability of HBSS can be solved simply and effectively by adopting a "two-step reduction method".

\subsection{Site description}

The Shenhu sea area is located in the Baiyun sag in the South China Sea (as shown in Fig. 1). In 2017 and 2020, China tried to produce hydrates in this region, establishing world records for gas production time and gas production volume. The average slope angle in the area is $3.3-3.8^{\circ}$, while the maximum slope angle can reach $30^{\circ}$. According to the seismic reflection profile and the location of the BSR (Bottom Simulating Reflector), the dimensions of the hydrate reservoir, such as depth of burial and thickness could be determined. The depth of seawater in this area can exceed $1000 \mathrm{~m}$. According to the lithology logs for the Shenhu drill hole, the distance from the seafloor to the top of the hydrate-bearing sediment ranges from $50-350 \mathrm{~m}$. The thickness of the hydrate-bearing strata ranged from 10-120 m.

\subsection{Dimensions of the numerical model}

Based on the actual geological conditions, referring to the relevant literature and making appropriate optimization, the dimensions of model are finally determined. The numerical model had a total length of $2590 \mathrm{~m}$, a slope length of $1600 \mathrm{~m}$, and horizontal submarine planes with lengths of $500 \mathrm{~m}$ above the slope and $500 \mathrm{~m}$ beyond the toe of the slope (Fig. 2). The slope angle was set at $6^{\circ}$, with the minimum height set at $700 \mathrm{~m}$ (Fig. 2). The trend (slope) of the hydrate reservoir was assumed to be parallel to the surface of the submarine slope (Fig. 2). The reservoir was assumed to be $60 \mathrm{~m}$ thick and the depth of burial $200 \mathrm{~m}$. In addition, the model was divided into overlying strata, surrounding strata, hydrate reservoirs and underlying strata. Prior to decomposition, the strength of the hydrate reservoir (dark blue slab in Fig. 2) was assumed to be stronger than that of the surrounding rocks (green strata in Fig. 2). It was also assumed for modelling purposes that as the degree of decomposition increased, its strength gradually decreased. Based on the results obtained from experiments to determine the mechanical properties of hydrate and related simulation research (Choi et al., 2020; Ghiassian and Grozic, 2013; Kong et al., 2018; Shi et al., 2019; Shi et al., 2015; Zhang et al., 2010), the mechanical parameters of the strata were determined after trial calculation, with the hydrate saturation about $25 \%$. The model is a twodimensional plane model, with a quadrilateral plane strain element. The mesh of hydrate reservoir and the area connected to it were refined. The model size and dimensions have been shown in Fig. 2. The mechanical parameters of the strata have been presented in Table 1. 
Table 1

Mechanical parameters of the strata using a step-wise approach to hydrate decomposition.

\begin{tabular}{|c|c|c|c|c|c|c|c|}
\hline \multicolumn{2}{|l|}{ Strata } & $\begin{array}{l}\text { Cohesion } \\
c / k P a\end{array}$ & $\begin{array}{l}\text { Friction } \\
\text { angle } \\
\varphi /\left(^{\circ}\right)\end{array}$ & $\begin{array}{l}\text { Dilation } \\
\text { angle } \\
\psi /\left(^{\circ}\right)\end{array}$ & $\begin{array}{l}\begin{array}{l}\text { Unit } \\
\text { weight }\end{array} \\
y /\left(\mathrm{kN} / \mathrm{m}^{3}\right)\end{array}$ & $\begin{array}{l}\text { Elastic } \\
\text { modulus } \\
\text { E/MPa }\end{array}$ & $\begin{array}{l}\text { Poisson } \\
\text { ratio } \\
v\end{array}$ \\
\hline \multicolumn{2}{|c|}{ Overlying strata } & 25 & 2.3 & 1.15 & 19.60 & 260 & 0.30 \\
\hline \multirow{5}{*}{$\begin{array}{l}\text { Hydrate- } \\
\text { bearing } \\
\text { sediments }\end{array}$} & Undecomposed & 350 & 3.5 & 1.75 & 19.88 & 370 & 0.35 \\
\hline & $\begin{array}{l}\text { Decomposition } \\
\text { by } 25 \%\end{array}$ & 270 & 3.4 & 1.70 & 19.87 & 305 & 0.34 \\
\hline & $\begin{array}{l}\text { Decomposition } \\
\text { by } 50 \%\end{array}$ & 195 & 3.3 & 1.65 & 19.86 & 230 & 0.33 \\
\hline & $\begin{array}{l}\text { Decomposition } \\
\text { by } 75 \%\end{array}$ & 110 & 3.1 & 1.55 & 19.85 & 175 & 0.32 \\
\hline & $\begin{array}{l}\text { Decomposition } \\
\text { by } 100 \%\end{array}$ & 20 & 2.9 & 1.45 & 19.84 & 125 & 0.31 \\
\hline \multicolumn{2}{|c|}{ Surrounding strata } & 35 & 3.2 & 1.60 & 19.70 & 300 & 0.30 \\
\hline \multicolumn{2}{|c|}{ Underlying strata } & 40 & 3.3 & 1.65 & 19.60 & 500 & 0.30 \\
\hline
\end{tabular}

The Mohr-Coulomb model is adopted as the constitutive model, and the boundary conditions are as follows: Horizontal displacement is limited at the left and right boundaries of the model, with displacement in all directions limited at the bottom boundary of the model. The load on the model included the overlying seawater pressure (depth) and its own gravity, with a simulated water depth of 1 $000 \mathrm{~m}$. The division of strata and boundary conditions of the model have been shown in Fig. 3.

Considering that the "two-step reduction method" proposed in this paper is mainly related to $C$ and $\varphi$, it is assumed that water and gas can be quickly discharged during hydrate decomposition. The decomposition process of sandy reservoir is simulated without considering the influence of pore pressure. Research on the impact of hydrate decomposition on fluid-solid coupling will be the subject of future research.

\section{Results And Discussion}

\subsection{Influence of hydrate decomposition}

Hydrate decomposition can be attributed to many potential factors, including earthquakes, volcanic eruptions, climate change and a fall in sea level. These events cause significant changes in temperature and pressure in sediments, which can subsequently cause large-scale decomposition of the hydrate (Lu et al., 2019). At the same time, considering the model size and the effective verification of the "two-step reduction method", the hydrate decomposition in this paper is assumed to occur evenly throughout the whole the reservoir. 


\subsubsection{Displacement change caused by hydrate decomposition}

The displacement nephogram with different degrees of decomposition is shown in Fig. 4. The illustrations in Fig. $4 b-4 d$ are unified to highlight the displacement caused by the increase in the degree of decomposition. The automatically generated legend in Fig. 4 a can be used to highlight the distribution of the magnitude of displacement in different areas of the nephogram.

It can be seen from Fig. 4 that the decomposition of hydrate causes a significant change in displacement. Interestingly, with the hydrate reservoir as the boundary, the upper displacement is wedge-shaped and the lower displacement is arc-shaped. Moreover, the peak displacement of the upper strata is concentrated near the top of the slope, while the displacement decreases closer to the foot of the slope. With the increase of degree of decomposition, the wedge-shaped area spreads from the top to the foot of the slope and the overall displacement increases continuously. The wedge-shaped distribution of displacement and the characteristics of large displacement at the top of the slope and smaller displacement at the foot of slope are closely related to the slope gradient. In addition, the "arc-shaped" distribution of the lower strata is very similar to the "arc-shaped" sliding surface of the landslide. Therefore, the formation of submarine landslides in hydrate-bearing sediments is directly related to the displacement changes caused by hydrate decomposition.

In order to obtain insight into additional changes in displacement caused by hydrate decomposition, two survey lines S1 (sloped) and S2 (vertical) were drawn in Fig. 4d. S1 is in the hydrate reservoir direction, while $S 2$ is a vertical section through the reservoir. Fig. 5 shows the displacement changes under different degrees of decomposition.

It can be clearly observed that the displacement curves for different degrees of decomposition show similar change rules. The slope displacement presents an inclined distribution with larger displacement at the top of slope and smaller displacement at the foot of slope. The peak displacement occurs at a certain distance from the top of the slope, not at the top of the slope. With an increase in the degree of hydrate decomposition, the overall displacement of the survey line increases and the peak value rises continuously. At the same time, it can be noted that the displacement of the area outside the hydrate reservoir in the horizontal direction changes little.

The displacement change in the vertical direction can be obtained from S2. In the vertical direction, the change in displacement caused by hydrate decomposition is in two different states, with the hydrate reservoir as the boundary. The displacement of strata above the hydrate reservoir is greatly affected by hydrate decomposition, with the extent of displacement positively related to the degree of hydrate decomposition. The displacement peak appears at the top of the model and decreases with an increase in the depth of burial. With the decrease of displacement, there is an obvious steep drop in the extent of displacement within the hydrate reservoir. The displacement of strata below the hydrate reservoir changes 
little and hence not by the same order of magnitude as that of the upper part, although it still shows a decreasing trend from top to bottom.

The distribution of displacement vectors with degree of decomposition set at $50 \%$ is shown in Fig. $5 \mathrm{c}$. The largest displacements are concentrated in the area above the hydrate reservoir, with the displacement at the top of the slope larger than that at the foot of the slope. In terms of the direction of displacement, the change in displacement caused by hydrate decomposition is dominated by vertical displacement, which leads to noticeable subsidence of the surface of the seabed. At the same time, due to the inclination of the slope, it will also produce horizontal displacement to the right.

To sum up, the range of influence of hydrate decomposition is limited. In the horizontal direction, the extent of influence is limited to the width of the hydrate reservoir. In the vertical direction, the extent of influence is largely limited to the hydrate reservoir and strata above it. Other areas in the model are less affected by hydrate decomposition.

\subsubsection{Stress change and strain caused by hydrate decomposition}

Hydrate decomposition is a dynamic process, with displacement changing in response to the redistribution of stress. The change in stress is not as obvious in the nephogram as the extent of displacement caused by hydrate decomposition (as shown in Fig. 6a).

The size of the hydrate reservoir is relatively small in comparison with the model as a whole model. The change of local stress caused by hydrate decomposition is much smaller than that of the whole model, so the change is not obvious in the nephogram as a whole. The stress analysis of the S2 line provided a better means to understand the nature of changes in the reservoir.

The stress variation curve of S2 is shown in Fig. 6b. It can be seen that stress shows strong regularity. In the lateral direction, the hydrate reservoir area is greatly affected by hydrate decomposition, while the area outside the hydrate reservoir is much less affected. It is precisely because of the different degree of influence that significant stress and abrupt change occurs at the boundary between the hydrate reservoir and surrounding strata. In the hydrate reservoir area, with the increase in the degree of decomposition, the stress decreases continuously, which is opposite to the change law of displacement. At the same time, it can be noted that when the degree of decomposition of hydrate is low ([25\%), the stress is characterized by a large value at the top of the slope and a small value at the foot of the slope. That is, there is a "nonuniform" distribution of stress in terms of magnitude along the slope. The stress peak appears at a certain distance from the top of the slope, which coincides with the displacement peak. With a further increase in the degree of hydrate decomposition, the "non-uniform" distribution of stress gradually disappears and the stress curve gradually tends to be flat. Therefore, hydrate decomposition has the effect of "dilution and homogenization" on the "non-uniform" distribution of slope stress. 
Elastic strain is not the main cause of material deformation and failure, while the tensile strength of geotechnical materials is very small. Inelastic shear strain was therefore selected for analysis in this study. At the same time, the true principal strain is used as a reference for comparative purposes. The distribution of strain with a degree of decomposition set at $50 \%$ is shown in Fig. 7. Fig. 7a is the nephogram of inelastic shear strain, while Fig. $7 \mathrm{~b}$ represents the distribution of the true principal strain vector. As shown in Fig. 7a, inelastic shear strain was significant in the hydrate reservoir area, while continuous strain below the reservoir can be regarded as the potential slip surface. The peak value of inelastic shear strain appears at both ends of the hydrate reservoir, that is, at the transition zone between the hydrate reservoir and the non-hydrate strata. Combined with the sudden change of stress in Fig. $6 \mathrm{~b}$, it can be seen that the strata are subjected strong shear stress at the boundary of the hydrate reservoir and surrounding strata. As a result, shear failure could easily occur in this area.

According to Fig. 7b, it can be clearly observed that the peak value of principal strain appears at the left end point of the hydrate reservoir, which is far greater than the principal strain value at other positions. In addition, the end point is connected with the principal strain at the top boundary of the model. Comparing Fig. 7a with Fig. 7b, the inelastic shear strain is highly consistent with the true strain distribution. This high level of concordance indicates that inelastic shear strain is probably the dominant type of strain caused by hydrate decomposition. Stated differently, inelastic shear strain can better characterize the failure of strata than other strain types. As the decomposition of the hydrate becomes more pronounced, the simultaneous advancement of the degree of deformation ultimately could cause shear failure and hence large-scale submarine landslides.

\subsubsection{Essence of hydrate decomposition}

Through the comparative analysis of displacement and stress, it can be seen that the decomposition of hydrate is a dynamic process of stress release and displacement increase, with the magnitude of displacement increase related to the degree of stress release. Due to the inclined nature of a submarine slope, the stress distribution along the slope after geostress balance is non-uniform. The stress values are greater at the top of a slope and smaller at the foot of a slope. In the process of hydrate decomposition, stress is released and its "non-uniform" distribution along the slope disappears. However, the displacement distribution is "non-uniform" again, and gradually decreases from the top to the foot of the slope, which corresponds to the released stress. Therefore, the main effect of hydrate decomposition is to transform the "stress inhomogeneity" distributed along the slope into "displacement inhomogeneity", with the displacement positively correlated with the stress difference before and after decomposition.

The patterns and processes discussed above can be explained in terms of momentum. Formula (3) can be used to describe the forces acting on a microelement of the hydrate reservoir during the decomposition of hydrate as follows:

$$
F \cdot \Delta t=\mathrm{d} m \cdot \Delta v(3)
$$

where $F$ is the average combined force on the micro element during hydrate decomposition; $\Delta t$ is the time of hydrate decomposition; $\mathrm{d} m$ is the mass of the micro element; and $\Delta v$ is the variation of average 
velocity of the micro element during hydrate decomposition.

It can be seen from Fig. 4 that the hydrate decomposition process is accompanied by an increase in displacement, that is, the combined force changes. The $\mathrm{d} m$ of each microelement is almost equal (the mass of discharged water and gas is very small relative to the mass of the reservoir), the $\Delta t$ is the same, and $\Delta v$ determined by $F$. According to Fig. $6 \mathrm{~b}$, before hydrate decomposition, the stress along the slope is larger at the top and smaller at the foot, but after hydrate decomposition, the stress along the slope is almost equal. Therefore, in this scenario, the $F$ on the micro element from the foot of the slope to the top of the slope gradually increases. That is, $\Delta v$ gradually increases from the foot of the slope to the top of the slope, and the closer to the top of the slope, the greater the displacement in the same period of time.

\subsubsection{Suggestions for hydrate exploitation}

According to the foregoing analysis, the range of displacement and changes in stress caused by hydrate decomposition are limited. In the horizontal direction, the extent of influence is the width of hydrate reservoir. In the vertical direction, it extent of influence is largely confined to the hydrate reservoir and strata above the hydrate reservoir. Especially near the top of the slope and in the transition area between the hydrate reservoir and non-hydrate strata, there will be a large change in displacement or shear stress. At present, a vertical hole is mainly used for gas hydrate test production (Yu et al., 2019b). Therefore, for low risk gas hydrate production in the actual submarine slope area, the hole should be located at the foot of the slope, or far away from the slope area, instead of near the top of the slope.

In addition, from the perspective of multi-well operation, when NGH exploitation is carried out in a submarine slope with poor stability, or if a submarine landslide could be caused by hydrate exploitation, the joint exploitation mode of "vertical shaft+horizontal well" in combination with multi-branch holes could be considered to mitigate the risk of slope failure. In this multi-well operational mode, horizontal wells should be set in the lower area of the hydrate reservoir, while the vertical wells should be set away from the slope area. This multi-well joint operation mode is also the development trend for future hydrate exploitation (Wilson et al., 2011; Yu et al., 2019a). The multi-well joint operational mode has been shown in Fig. 8.

\subsection{Landslide development process}

By adopting the "two-step reduction method", after analyzing the effect of hydrate decomposition, it is convenient to reduce the overall strength of a submarine slope through a second reduction analysis step, and then to obtain the development process of a submarine landslide. Fig. 9 shows the development process for the plastic zone with different reduction factors, when the degree of decomposition is $75 \%$.

As shown in Fig. 9, the development process of submarine landslide presents a strong regularity and shows an obvious progressive relationship in stages, and hydrate decomposition can induce submarine landslides. First of all, when hydrate decomposition is finished, the plastic damage caused by hydrate decomposition is mainly manifested at the boundary between two ends of the hydrate reservoir (the boundary between the hydrate reservoir and non-hydrate reservoir), and the left boundary area is connected with the horizontal submarine plane at the top of the model (as shown in Fig. 9a). With the 
weakening of the overall strength of the submarine slope, the plastic zone develops further. An obvious plastic failure zone extends downward from the junction at the left end of the hydrate reservoir (as shown in Fig. 9b). If Fig. 9b is compared with Fig. 7, it can be seen that the development of the plastic zone is highly consistent with the shear failure and principal strain distribution caused by hydrate decomposition, especially the potential slip surface, with which it basically coincides. This indicates that hydrate decomposition can induce a submarine landslide. In other words, the submarine landslide after hydrate decomposition is the further development of shear failure based on the influence of hydrate decomposition.

With a further increase of the reduction factor, the plastic zone at the right boundary of the hydrate reservoir connects with the right submarine plane at the top of the model (as shown in Fig. 9c). On this basis, the reduction factor continues to increase and the lower potential slip surface continues to expand, which connects with the plastic zone at the right end of the reservoir (as shown in Fig. 9d). At this point, a plastic zone with overall connectivity is formed from the top to the foot of the slope and a landslide takes place. Eventually, a large-scale landslide occurred, and the model was terminated, as the calculation did not converge. The final safety factor was 1.875 when the degree of decomposition was $75 \%$.

To sum up, the processes associated with submarine landslides, under the influence of hydrate decomposition, can be divided into the following stages:

(1) First, hydrate decomposition leads to plastic failure at the interface between the hydrate reservoir and non-hydrate reservoir. The plastic zone at the junction near the top of the slope runs through the top of the slope.

(2) Second, the plastic zone at the junction near the top of the slope extends deep into the strata and forms a potential slip surface.

(3) Third, the plastic zone near the junction of the foot of the slope extends to the top and connects with the horizontal submarine plane at the foot of the slope.

(4) Then, the potential slip surface is connected with the plastic zone at the foot of the slope, forming a plastic zone from the top to the foot of the slope.

(5) Finally, the penetrating plastic zone develops continuously and a large-scale submarine landslide takes place.

\subsection{Safety factor}

The safety factors of submarine slopes under different degrees of decomposition were counted. At the same time, after hydrate decomposition $\left(F_{\mathrm{r}}=1\right)$, the peak value of the plastic zone before overall strength reduction of the submarine slope was also counted. The variation of the safety factor values and peak values for the plastic zone under different degrees of decomposition have been shown in Fig. 10. 
According to Fig. 10, with an increase in the degree of hydrate decomposition, the safety factor gradually decreases. While the peak values of the plastic zone increase monotonically with an increase in the degree of decomposition. According to the relationship between plastic failure and safety factor, we can explain the relationship between the degree of hydrate decomposition and submarine slope stability from different perspectives. On the one hand, the increase in hydrate decomposition will inevitably lead to a decrease in hydrate reservoir strength. According to the principle of strength reduction, the decrease of cohesion and internal friction angle of the hydrate reservoir will lead to a decrease of "overall strength" of the macroscopic submarine slope. On the other hand, according to the analysis above, the decomposition of the hydrate will cause significant changes in stress and displacement, with the geostress redistributed as a consequence. Especially in the boundary area between hydrate reservoir and non-hydrate reservoir, it is accompanied by significant stress concentration and shear strain. This dual action of stress and displacement will have a profound impact on the submarine slope. In other words, plastic failure (landslide) will be induced by hydrate decomposition, or what could be called a "memory effect and historical effect" of strata stress. This comprehensive influence increased with an increase in the degree of hydrate decomposition.

The safety factor of hydrate changed from 1.883 to 1.862 during the transition from undecomposed to completely decomposed. This showed that the influence of hydrate decomposition on the overall stability of a submarine slope is relatively small, which is consistent with the conclusion that the range of influence of hydrate decomposition is limited. It should be pointed out that the influence of hydrate decomposition on submarine slope is controlled by the relative size of the hydrate reservoir and submarine slope. That is, the influence of hydrate decomposition is relative.

The displacement nephogram and vector distribution within the plastic zone just passing through from the top to the foot of the slope have been shown in Fig. 11 (decomposition by 100\%). In Fig. 11a, we can see that in the initial stage when the plastic zone runs from the top to the foot of the slope, a large range of strata move along the potential slip surface as a whole. At this time, the overall form of the landslide has taken shape. The displacement nephogram of the area above the hydrate reservoir is similar to that in Fig. 4, which still shows a wedge-shaped distribution of displacement near the top of the slope, rather than a circular arc-shaped distribution similar to the potential slip surface. This indicates that at this time, the potential slip surface is formed in the deep stratum (below the hydrate layer) and the landslide begins. However, the shallow stratum (above the hydrate reservoir) has not yet formed a continuous slip surface. At the same time, the whole is distributed in circular arc shape, while the upper part is distributed in a wedge shape, which can also be regarded as a precursor to the formation of a large-scale submarine landslide.

As shown in Fig. 11b, when the safety factor changes from only 1.851 to 1.852 , the maximum displacement of the slope increases from $21.54 \mathrm{~m}$ to $87.2 \mathrm{~m}$ The displacement nephogram is arc-shaped, and a large-scale submarine landslide is formed. It can be seen that a submarine landslide presents dual characteristics in time and space. In time, the change is extremely fast, while in space, it is accompanied 
by a large-scale change from the top to the foot of the slope. This is also the most fundamental reason why submarine landslides can not be effectively monitored in the natural environment.

In Fig. 11, the maximum displacement appears at the top of the sliding surface, with the top of the slope moving downward, while the foot of the slope moves upward under the action of the landslide. In addition, the displacement in this process is mainly horizontal. It should be pointed out that after the landslide begins to form (the plastic zone runs through), the large-scale displacement is mainly dominated by the strata sliding forming the continuous sliding surface, and is no longer controlled by the strata strength.

\section{Conclusions}

(1) The proposed "two-step reduction method" can be used to consider the effects of the initial stress balance, hydrate decomposition and strength reduction on submarine slope stability. The success of the method meant the tedious steps of repeated initial balancing and parameter assignment could be avoided.

(2) Hydrate decomposition is a dynamic process of stress release that results in an increase in slope displacement. The main effect of hydrate decomposition is transformation of the "stress inhomogeneity" distributed along the slope into "displacement inhomogeneity". The displacement is positively correlated with the stress difference before and after decomposition.

(3) When the stability of submarine slopes is low and hydrate exploitation takes place, submarine landslides can be triggered. The joint exploitation mode of "vertical well+horizontal well" combined with multi-branch holes should be considered to mitigate the risk. Horizontal wells should be set in the lower reaches of the hydrate reservoir, while vertical wells should be set away from the slope.

(4) A submarine landslide, especially the formation of a sliding surface, will be induced by hydrate decomposition.

(5) The final formation of submarine landslide is a gradual development process, while the submarine landslide is an event with dual characteristics of sudden change in time and large-scale in space.

\section{Declarations}

\section{Acknowledgements}

This work was financially supported by the National Natural Science Foundation of China (project grants 12172187 and 51778311). The support is gratefully acknowledged with thanks.

\section{Declaration of interest statement}


We declare that we have no financial and personal relationships with other people or organizations that can inappropriately influence our work, there is no professional or other personal interest of any nature or kind in any product, service and/or company that could be construed as influencing the position presented in, or the review of, the manuscript entitled "Influence of hydrate exploitation on stability of submarine slopes".

\section{References}

1. Bishop AW (1955) The use of the slip circle in the stability analysis of slopes. Geotechnique 5(1):717

2. Bolla A, Paronuzzi P (2020) Numerical investigation of the pre-collapse behavior and internal damage of an unstable rock slope. Rock Mech Rock Eng 53(5):2279-2300. https://doi.org/10.1007/s00603-019-02031-z

3. Boswell R, Collett TS (2011) Current perspectives on gas hydrate resources. Energy Environ Sci 4(4):1206-1215. https://doi.org/10.1039/c0ee00203h

4. Boswell R, Collett TS, Frye M, Shedd W, McConnell DR, Shelander D (2012) Subsurface gas hydrates in the northern Gulf of Mexico. Mar Pet Geol 34(1):4-30. https://doi.org/10.1016/j.marpetgeo.2011.10.003

5. Chand S, Minshull TA (2004) The effect of hydrate content on seismic attenuation: A case study for Mallik 2L-38 well data, Mackenzie delta, Canada. Geophys Res Lett 31(14):L14609. https://doi.org/10.1029/2004GL020292

6. Chen W, Liu C, Li Y, Chen G, Jeng D, Liao C, Yu J (2020) An integrated numerical model for the stability of artificial submarine slope under wave load. Coast Eng 158:103698. https://doi.org/10.1016/j.coastaleng.2020.103698

7. Cheng YM, Yip CJ (2007) Three-dimensional asymmetrical slope stability analysis extension of Bishop's, Janbu's, and Morgenstern-Price's techniques. J Geotech GeoEnviron Eng 133(12):15441555. https://doi.org/10.1061/(ASCE)1090-0241(2007)133:12(1544)

8. Choi JH, Lin JS, Dai S, Lei L, Seol Y (2020) Triaxial compression of hydrate-bearing sediments undergoing hydrate dissociation by depressurization. Geomechanics for Energy the Environment 23:100187. https://doi.org/10.1016/j.gete.2020.100187

9. Collett TS (2005) Results at Mallik highlight progress in gas hydrate energy resource research and development. Petrophysics 46(3):237-243. https://doi.org/10.1007/s00126-005-0006-x

10. Elger J, Berndt C, Ruepke L, Krastel S, Gross F, Geissler WH (2018) Submarine slope failures due to pipe structure formation. Nat Commun 9:715. https://doi.org/10.1038/s41467-018-03176-1

11. Englezos P (1993) Clathrate hydrates. Industrial Engineering Chemistry Research, 32: 1251-1274. https://doi.org/ 10.1021/ie00019a001

12. Ghiassian H, Grozic JLH (2013) Strength behavior of methane hydrate bearing sand in undrained triaxial testing. Mar Pet Geol 43:310-319. https://doi.org/10.1016/j.marpetgeo.2013.01.007 
13. Jiang M, Sun C, Crosta GB, Zhang W (2015) A study of submarine steep slope failures triggered by thermal dissociation of methane hydrates using a coupled CFD-DEM approach. Eng Geol 190:1-16. https://doi.org/10.1016/j.enggeo.2015.02.007

14. Kimura S, Ito T, Noda S, Suzuki K, Yasuda H, Minagawa H (2019) Water permeability evolution with faulting for unconsolidated turbidite sand in a gas-hydrate reservoir in the eastern Nankai Trough area of Japan. Journal of Geophysical Research: Solid Earth 124(12):13415-13426. https://doi.org/10.1029/2019JB018102

15. Koh CA, Westacott RE, Zhang W, Hirachand K, Creek JL, Soper AK (2002) Mechanisms of gas hydrate formation and inhibition. Fluid Phase Equilib 194:143-151. https://doi.org/10.1016/S03783812(01)00660-4

16. Kong L, Zhang Z, Yuan Q, Liang Q, Shi Y, Lin J (2018) Multi-factor sensitivity analysis on the stability of submarine hydrate-bearing slope. China Geology 1(3):367-373. https://doi.org/10.31035/cg2018051

17. Kwon TH, Cho GC (2012) Submarine Slope Failure Primed and Triggered by Bottom Water Warming in Oceanic Hydrate-Bearing Deposits. Energies 5(8):2849-2873. https:// doi.org/10.3390/en5082849

18. Leynaud D, Mienert J, Nadim F (2004) Slope stability assessment of the Helland Hansen area offshore the mid-Norwegian margin. Mar Geol 213(1-4):457-480. https://doi.org/10.1016/j.margeo.2004.10.019

19. Li C, Wu S, Zhu Z et al (2014) The assessment of submarine slope instability in Baiyun Sag using gray clustering method. Nat Hazards 74(2):1179-1190. https://doi.org/10.1007/s11069-014-1241-1

20. Li J, Ye J, Qin X, Qiu H, Wu N, Lu H, Xie W, Lu J, Peng F, Xu Z, Lu C, Kuang Z, Wei J, Liang Q, Lu H, Kou $B$ (2018) The first offshore natural gas hydrate production test in South China Sea. China Geology 1(1):5-16. https://doi.org/10.31035/cg2018003

21. Li Y, Liu L, Jin Y, Wu N (2021) Characterization and development of marine natural gas hydrate reservoirs in clayey-silt sediments: A review and discussion. Advances in Geo-Energy Research 5(1):75-86. https://doi.org/10.46690/ager.2021.01.08

22. Li YX, Yang XL (2019) Soil-slope stability considering effect of soil-strength nonlinearity. Int J Geomech 19(3):04018201. https://doi.org/10.1061/(ASCE)GM.1943-5622.0001355

23. Li Z, Han J (2021) Environmental safety and low velocity of the development of submarine natural gas hydrate with examples of test production in South China Sea. Environ Sci Pollut Res 28(5):6259-6265. https://doi.org/10.1007/s11356-020-12159-z

24. Liu L, Lu X, Zhang X, Liu C, Du B (2017) Numerical simulations for analyzing deformation characteristics of hydrate-bearing sediments during depressurization. Advances in Geo-Energy Research 1(3):135-147. https://doi.org/10.26804/ager.2017.03.01

25. Liu T, Ding L, Meng F, Li X, Zheng Y (2021) Stability analysis of anti-dip bedding rock slopes using a limit equilibrium model combined with bi-directional evolutionary structural optimization (BESO) method. Comput Geotech 134:104116. https://doi.org/10.1016/j.compgeo.2021.104116 
26. Lu X, Zhang X, Wang S (2019) Advances on the safety related with natural gas hydrate exploitation. Chinese Science: Physics Mechanics Astronomy 49(03):7-37. https://doi.org/10.1360/SSPMA201800213. (in Chinese).

27. Luo Y, Liu W, He S et al (2018) Dynamic process simulation of rainfall-induced Sanxicun landslide based on a thermo-poro-elastic approach. Nat Hazards 92(1):415-428. https://doi.org/10.1007/s11069-018-3209-z

28. Makogon YF, Holditch SA, Makogon TY (2005) Russian field illustrates gas-hydrate production. Oil Gas J 103(5):43-47

29. Masson DG, Arzola RG, Wynn RB, Hunt JE, Weaver PPE (2011) Seismic triggering of landslides and turbidity currents offshore Portugal. Geochem Geophys Geosyst 12(12):Q12011. https://doi.org/10.1029/2011gc003839

30. Moridis GJ, Kowalsky MB, Pruess K (2007) Depressurization-induced gas production from class-1 hydrate deposits. Society of Petroleum Engineers Reservoir Evaluation Andengineering 10(05):458481. https://doi.org/10.2118/97266-PA

31. Rutqvist J, Moridis GJ, Grover T, Collett T (2009) Geomechanical response of permafrost-associated hydrate deposits to depressurization-induced gas production. J Petrol Sci Eng 67(1-2):1-12. https://doi.org/10.1016/j.petrol.2009.02.013

32. Shi Y, Liang Q, Yang J, Yuan Q, Wu X, Kong L (2019) Stability analysis of submarine slopes in the area of the test production of gas hydrate in the South China Sea. China Geology 2(3):274-284. https://doi.org/10.31035/cg2018122

33. Shi Y, Zhang X, Lu X, Wang S, Wang. A (2015) Experimental study on the static mechanical properties of hydrate-bearing silty-clay in the South China Sea. Chinese Journal of Theoretical Applied Mechanics 47(03):521-528. https://doi.org/10.6052/0459-1879-14-424. (in Chinese).

34. Song B, Cheng Y, Yan C, Han Z, Ding J, Li Y, Wei J (2019a) Influences of hydrate decomposition on submarine landslide. Landslides 16(11):2127-2150. https://doi.org/10.1007/s10346-019-01217-4

35. Song B, Cheng Y, Yan C, Han Z, Ding J, Li Y, Wei J (2019b) Seafloor subsidence response and submarine slope stability evaluation in response to hydrate dissociation. J Nat Gas Sci Eng, 65: 197211. https://doi.org/ 10.1016/j.jngse.2019.02.009

36. Sultan N, Cochonat P, Foucher JP, Mienert J (2004) Effect of gas hydrates melting on seafloor slope instability. Mar Geol 213(1):379-401. https://doi.org/10.1016/j.margeo.2004.10.015

37. Sun J, Zhang L, Ning F, Liu T, Fang B, Li Y, Liu C, Jiang G (2021) Research status and prospects of increasing production from gas hydrate reservoirs. Acta Petrolei Sinica 42(4):523-540. https://doi.org/10.7623/syxb202104009. (in Chinese).

38. Tan L, Liu F, Huang Y, Crosta G, Frattini P, Cen X (2021) Production-induced instability of a gentle submarine slope: Potential impact of gas hydrate exploitation with the huff-puff method. Eng Geol 289:106174. https://doi.org/10.1016/j.enggeo.2021.106174

39. Tang D, Jiang Z, Yuan T, Li Y (2020) Stability analysis of soil slope subjected to perched water condition. KSCE J Civ Eng 24(9):2581-2590. https://doi.org/10.1007/s12205-020-1728-0 
40. Thakur NK (2010) Gas hydrates as alternative energy resource-seismic methods. Curr Sci 99(2):181189. https://doi.org/10.1371/journal.pone.0011764

41. Tupsakhare SS, Kattekola S, Castaldi MJ (2017) An application of the results from the large-scale thermal stimulation method of methane hydrate dissociation to the field tests. Industrial Engineering Chemistry Research, 56 (15): 4588-4599. https://doi.org/10.1021/acs.iecr.7b00553

42. Wang H, Tian G, Zhao Y et al (2019) Dynamic modeling of Meiping landslide process. Nat Hazards 96(2):879-892. https://doi.org/10.1007/s11069-019-03575-7

43. Wang H, Zhang B, Mei G, Xu N (2020) A statistics-based discrete element modeling method coupled with the strength reduction method for the stability analysis of jointed rock slopes. Eng Geol 264:105247. https://doi.org/10.1016/j.enggeo.2019.105247

44. Wang Y, Li X, Li G, Huang N, Feng J (2014) Experimental study on the hydrate dissociation in porous media by five-spot thermal huff and puff method. Fuel 117:688-696. https://doi.org/10.1016/j.fuel.2013.09.088

45. Wilson SJ, Hunter RB, Collett TS, Hancock S, Boswell R, Anderson BJ (2011) Alaska North Slope regional gas hydrate production modeling forecasts. Mar Pet Geol 28(2):460-477. https://doi.org/10.1016/j.marpetgeo.2010.03.007

46. Yu T, Guan G, Abudula A, Yoshida A, Wang D, Song Y (2019a) Application of horizontal wells to the oceanic methane hydrate production in the Nankai Trough, Japan. J Nat Gas Sci Eng 62:113-131. https://doi.org/10.1016/j.jngse.2018.11.027

47. Yu T, Guan G, Abudula A, Yoshida A, Wang D, Song Y (2019b) Gas recovery enhancement from methane hydrate reservoir in the Nankai Trough using vertical wells. Energy 166:834-844. https://doi.org/10.1016/j.energy.2018.10.155

48. Zaniboni F, Armigliato A, Tinti S (2016) A numerical investigation of the 1783 landslide-induced catastrophic tsunami in Scilla. Italy Natural Hazards 84(S2):455-470. https://doi.org/10.1007/s11069-016-2639-8

49. Zhang M, Niu M, Shen S et al (2021) Review of natural gas hydrate dissociation effects on seabed stability. Nat Hazards 107(2):1035-1045. https://doi.org/10.1007/s11069-021-04629-5

50. Zhang X, Wang S, Li Q, Zhao J, Wang A (2010) Experimental study of mechanical properties of gas hydrate deposits. Rock Soil Mechanics 31(10):3069-3074. (in Chinese)

51. Zhang X, Zhang L, Li Z (2018) Reliability analysis of soil slope based on upper bound method of limit analysis. Rock Soil Mechanics 39(05):1840-1850. https://doi.org/10.16285/j.rsm.2017.1894. (in Chinese).

52. Zheng D, Nian T, Liu B, Liu M, Yin P, Huo Y (2019) Investigation of the stability of submarine sensitive clay slopes underwave-induced pressure. Marine Georesources Geotechnology 37(1):116-127. https://doi.org/10.1080/1064119X.2018.1481470

53. Zhu Y, Wang P, Pang S, Zhang S, Xiao R (2021) A review of the resource and test production of natural gas hydrates in China. Energy Fuels 35(11):9137-9150.

https://doi.org/10.1021/acs.energyfuels.1c00485 
54. Zienkiewicz OC, Humpheson C, Lewis RW (1975) Associated and non-associated visco-plasticity and plasticity in soil mechanics. Geotechnique 25(4):671-689. https://doi.org/10.1680/geot.1975.25.4.671

\section{Figures}
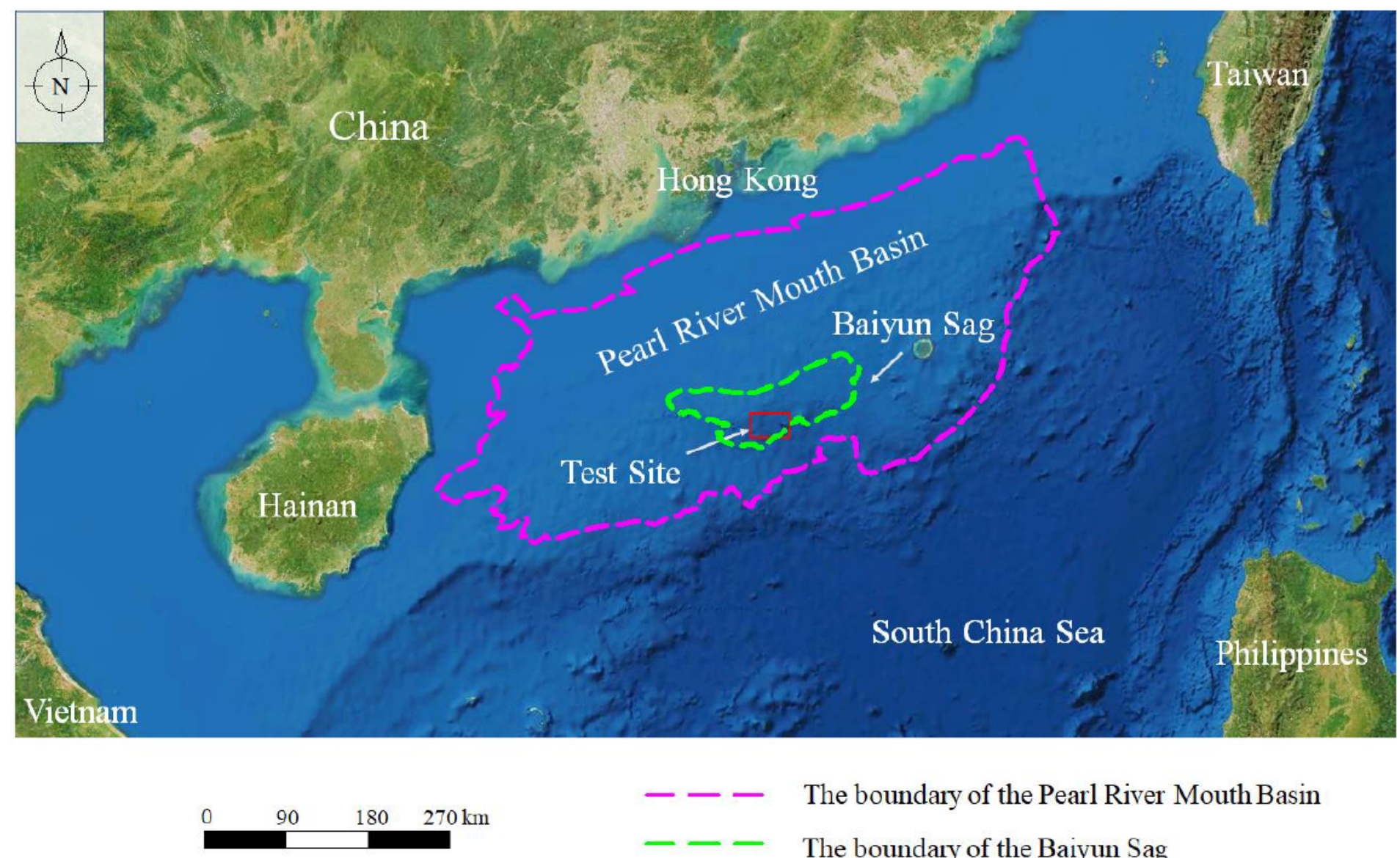

- - - The boundary of the Pearl River Mouth Basin

- - - The boundary of the Baiyun Sag

$\square$ Test site

\section{Figure 1}

Location of the study area in the South China Sea. 


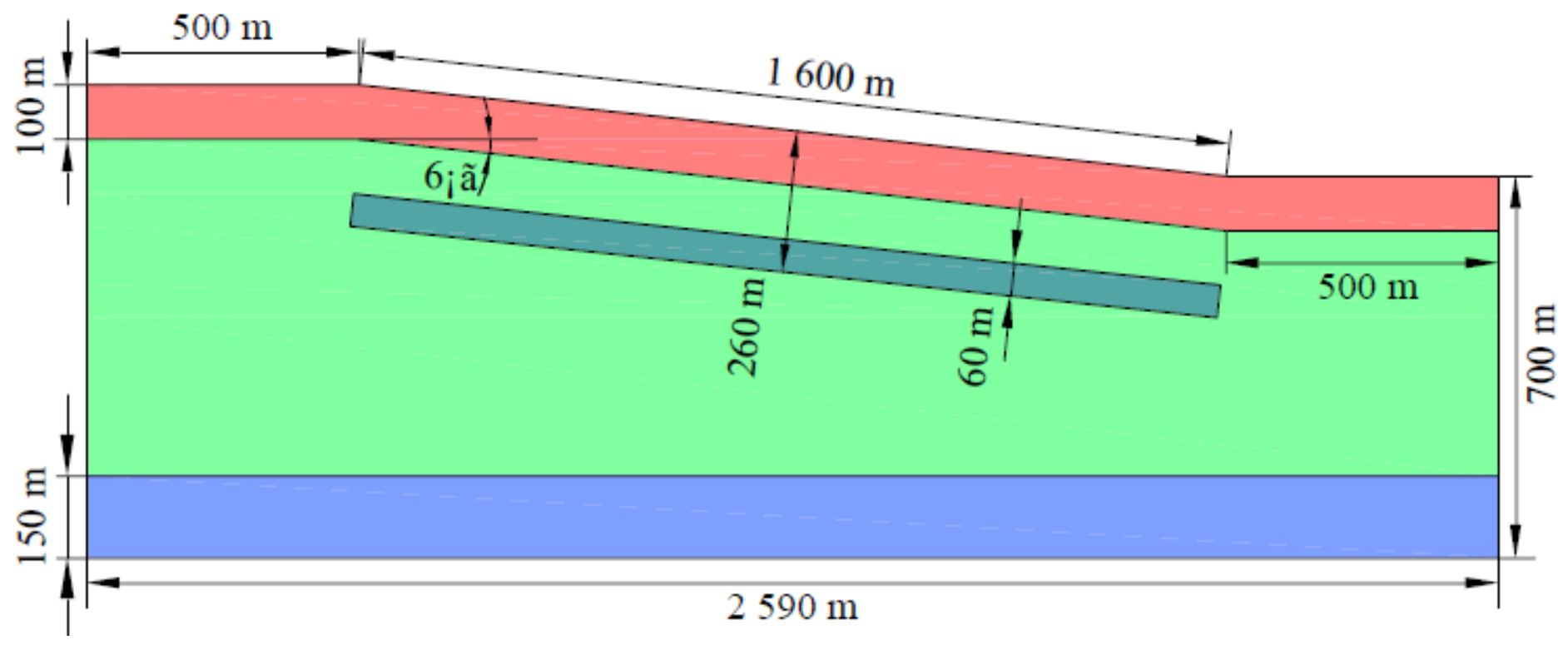

Figure 2

Schematic diagram of the model, components and dimensions used in the study (light blue = underlying strata; green = surrounding strata; pink = overlying strata; dark blue = hydrate reservoir) .

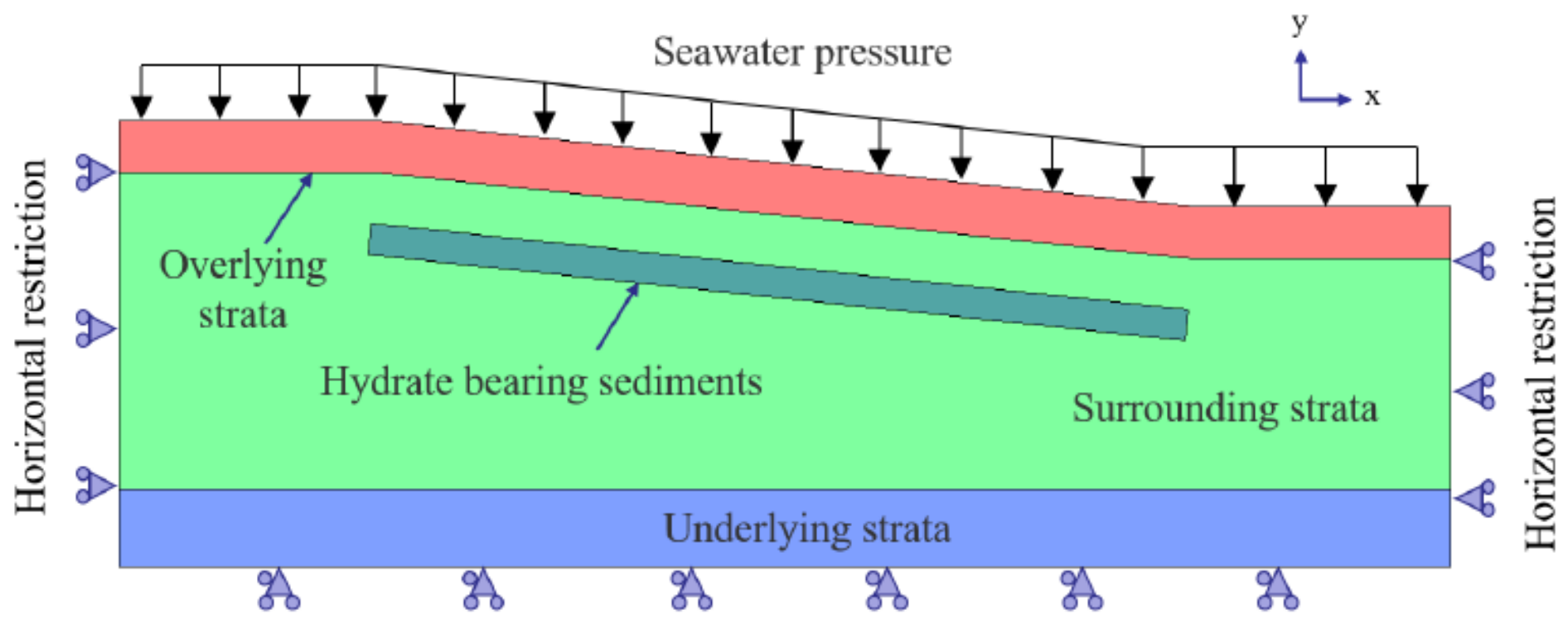

Vertical and horizontal restriction

Figure 3

The division of strata and boundary conditions for the model. 


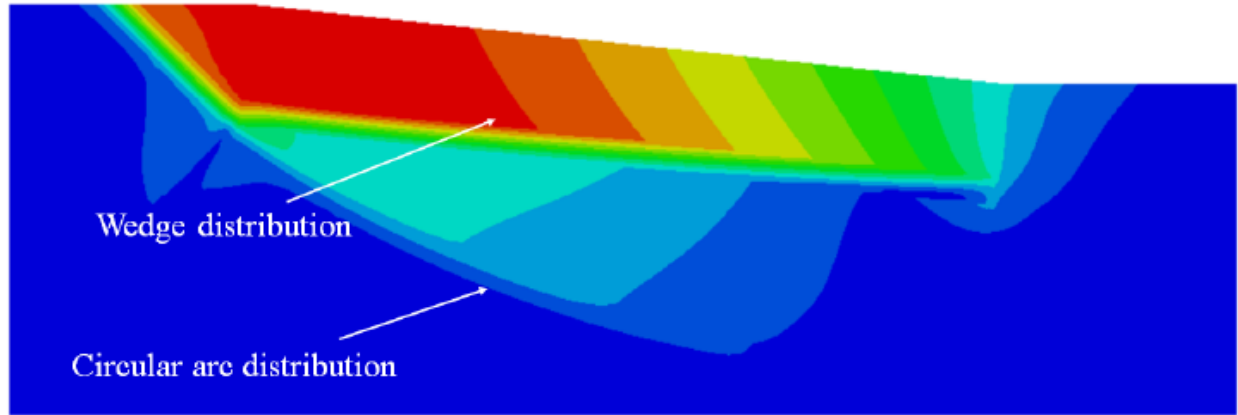

(a) Degree of decomposition (25\%)
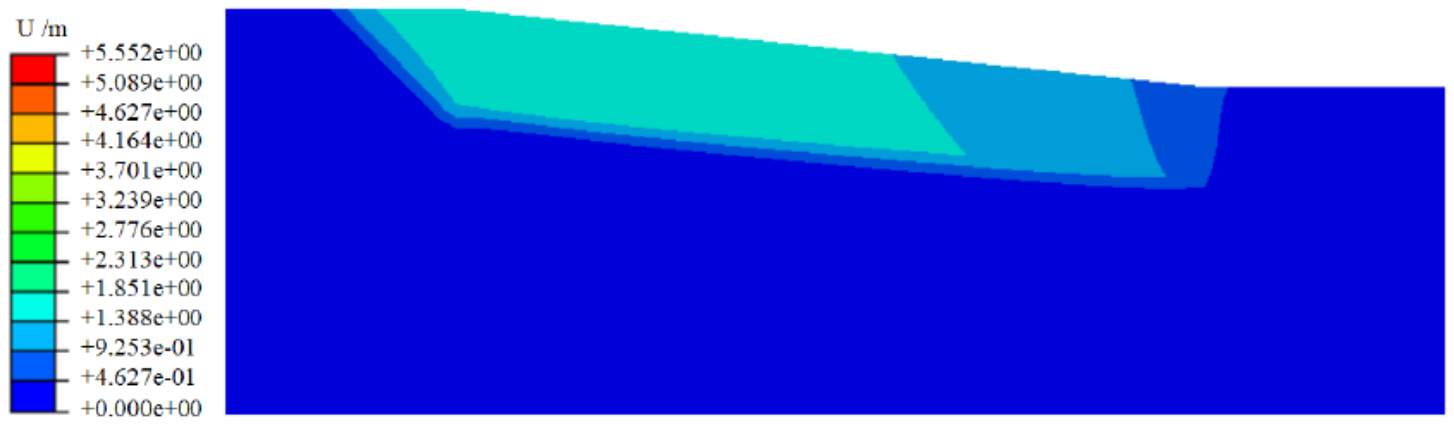

(b) Degree of decomposition (50\%)

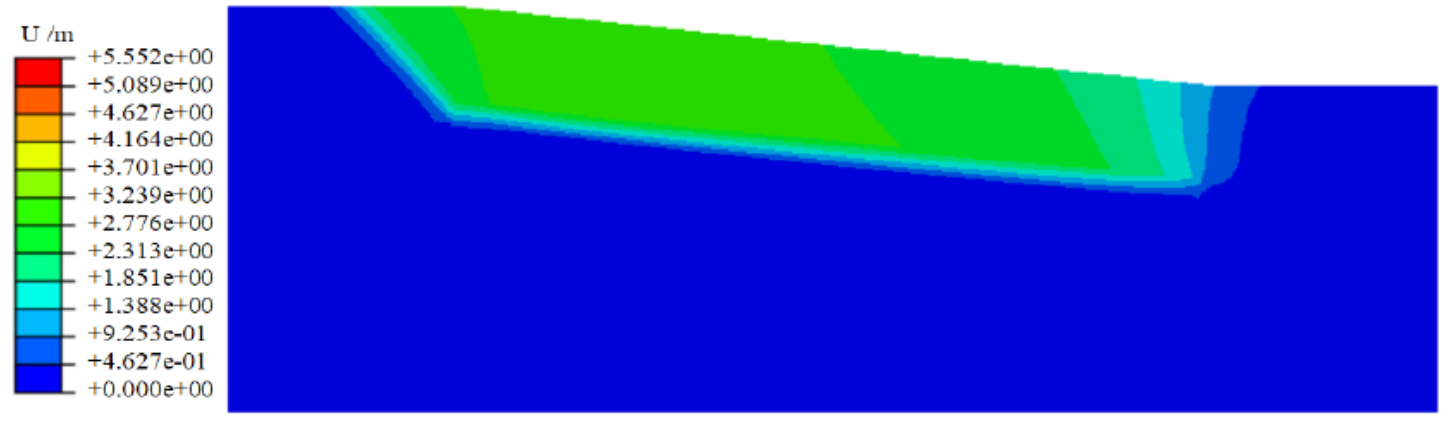

(c) Degree of decomposition (75\%)
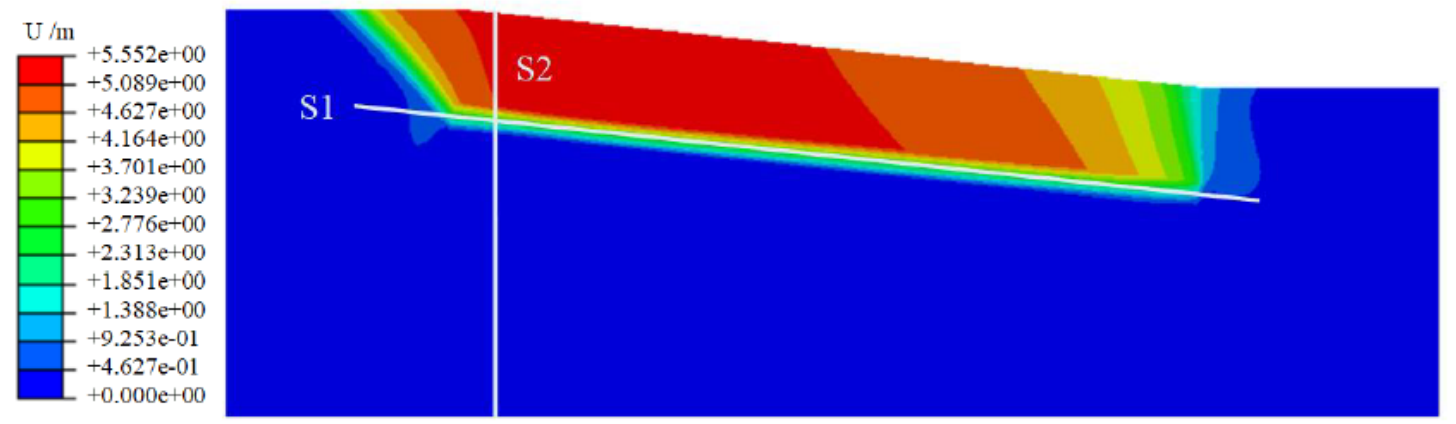

(d) Degree of decomposition (100\%)

\section{Figure 4}

Displacement nephogram with different degrees of decomposition. 


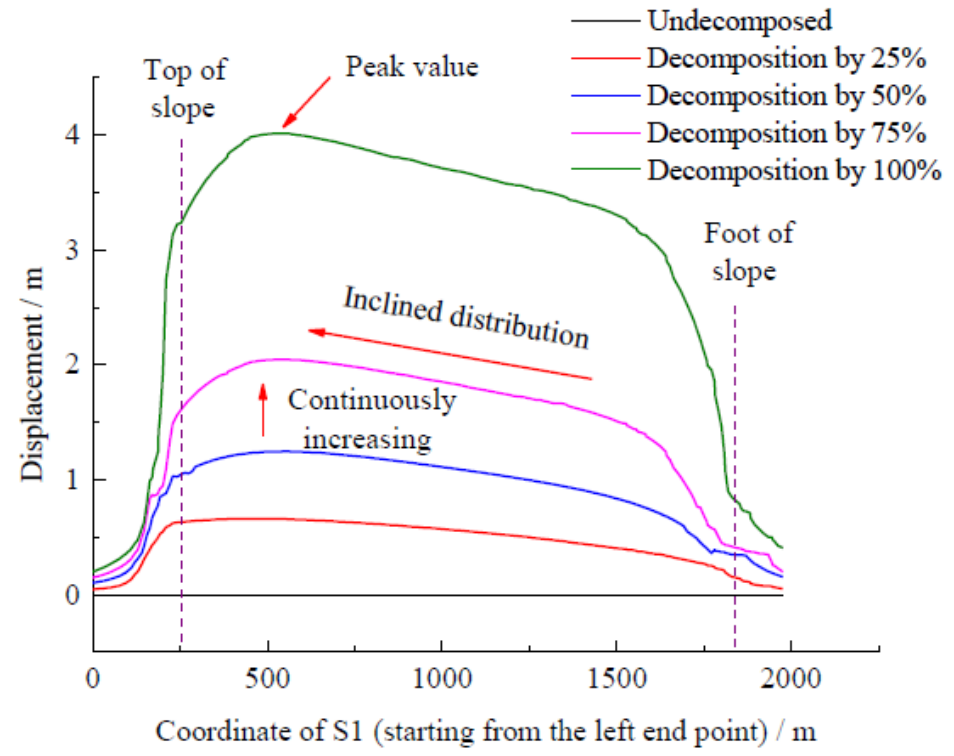

(a) Displacement change of S1

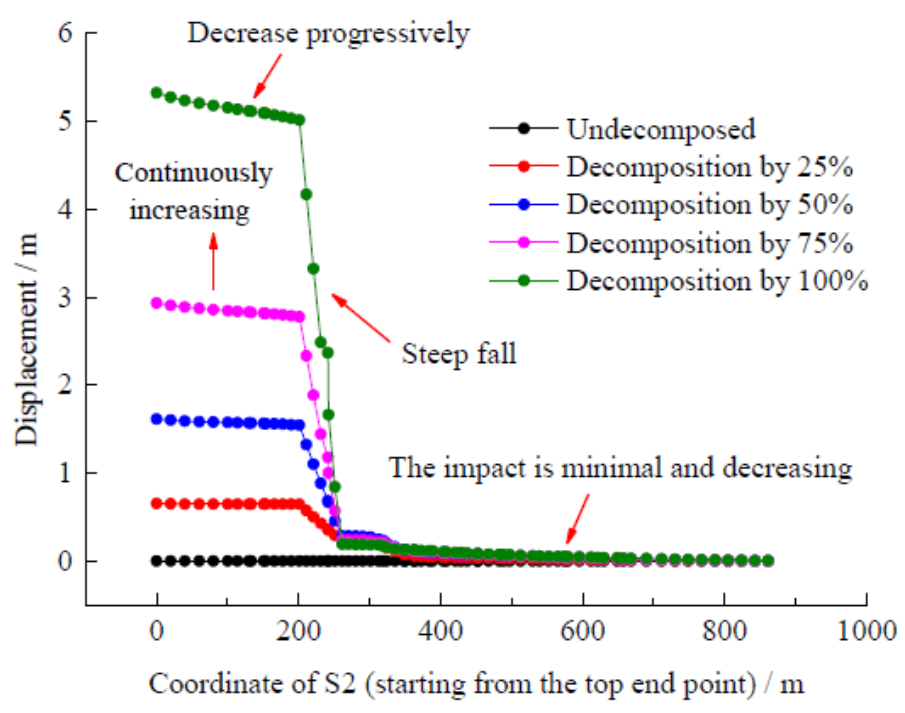

(b) Displacement change of S2

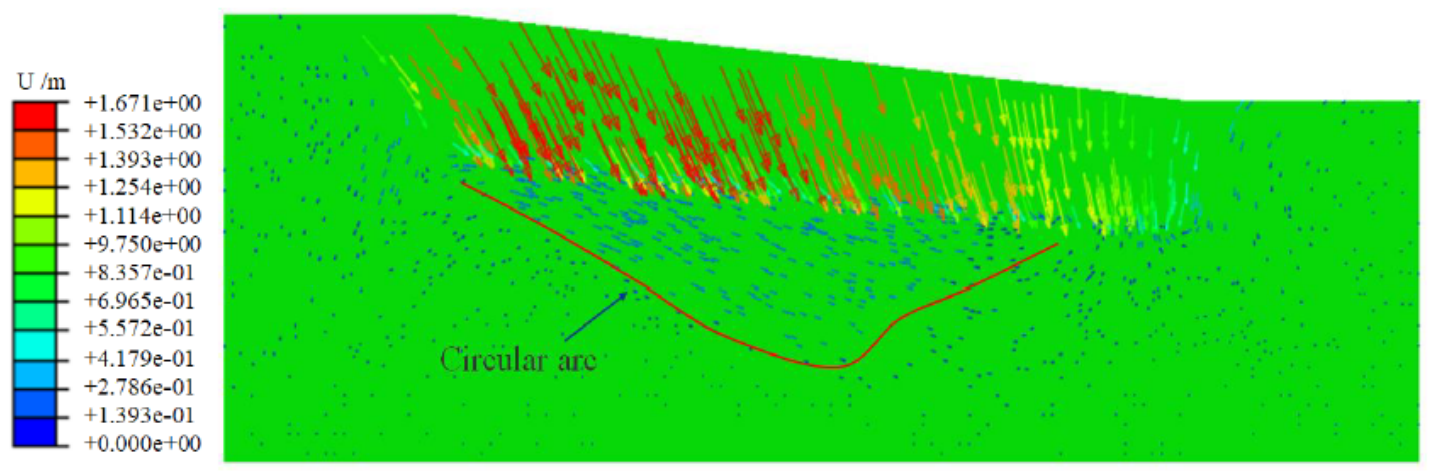

(c) Distribution of displacement vectors with degree of decomposition (50\%)

\section{Figure 5}

Displacement with different degrees of decomposition. 
Stress / $\mathrm{MPa}$

$+2.705 \mathrm{e}+00$

$+2.519 \mathrm{e}+00$

$+2.333 \mathrm{e}+00$

$+2.146 \mathrm{e}+00$

$+1.960 \mathrm{e}+00$

$+1.774 \mathrm{e}+00$

$+1.588 \mathrm{e}-01$

$+1.401 \mathrm{e}-01$

$+1.215 \mathrm{e}-01$

$+1.029 \mathrm{e}-01$

$+8.427 \mathrm{e}-01$

$+6.565 \mathrm{e}-01$

$+4.703 \mathrm{e}-01$

(a) Stress nephogram with degree of decomposition (50\%)

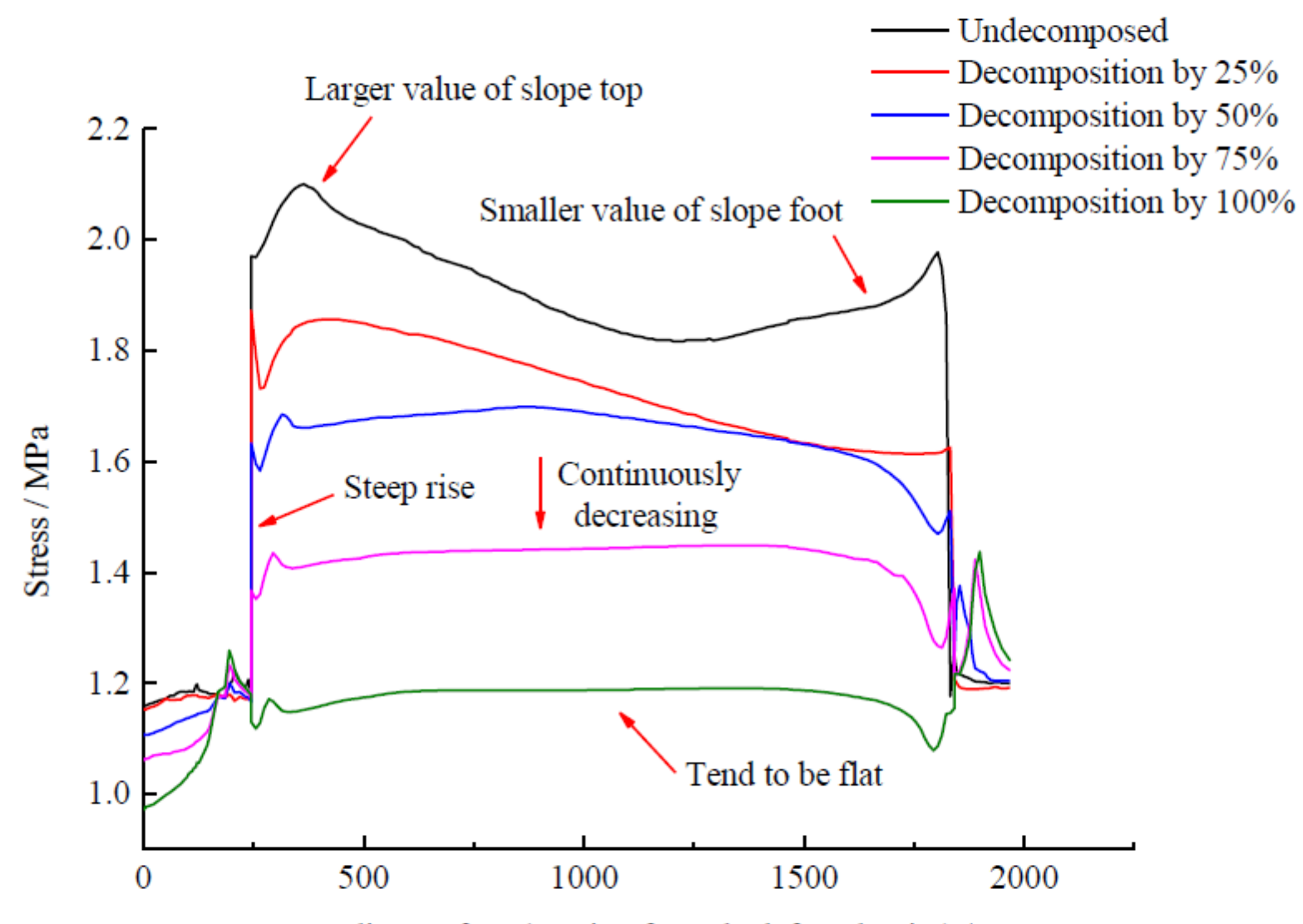

Coordinate of S1 (starting from the left end point) $/ \mathrm{m}$

(b) Stress variation of S2

Figure 6

Stress nephogram and stress variation of S2. 
EE. 正12
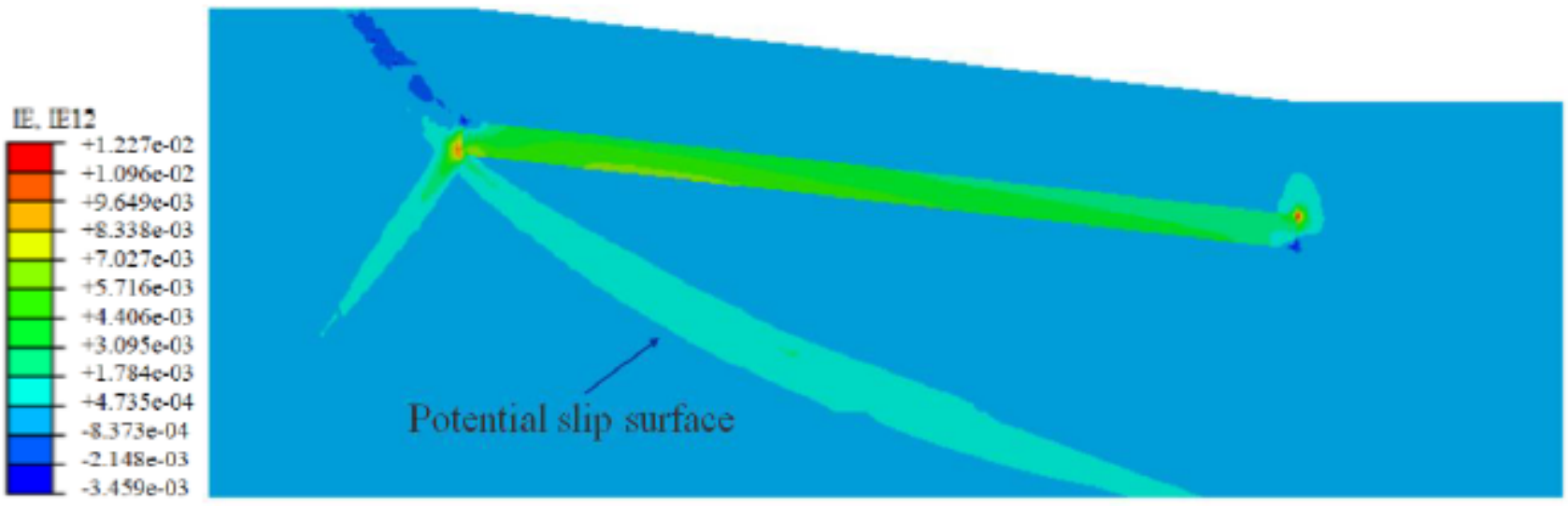

(a) Distribution of inelastic shear strain

E, Max.Principal
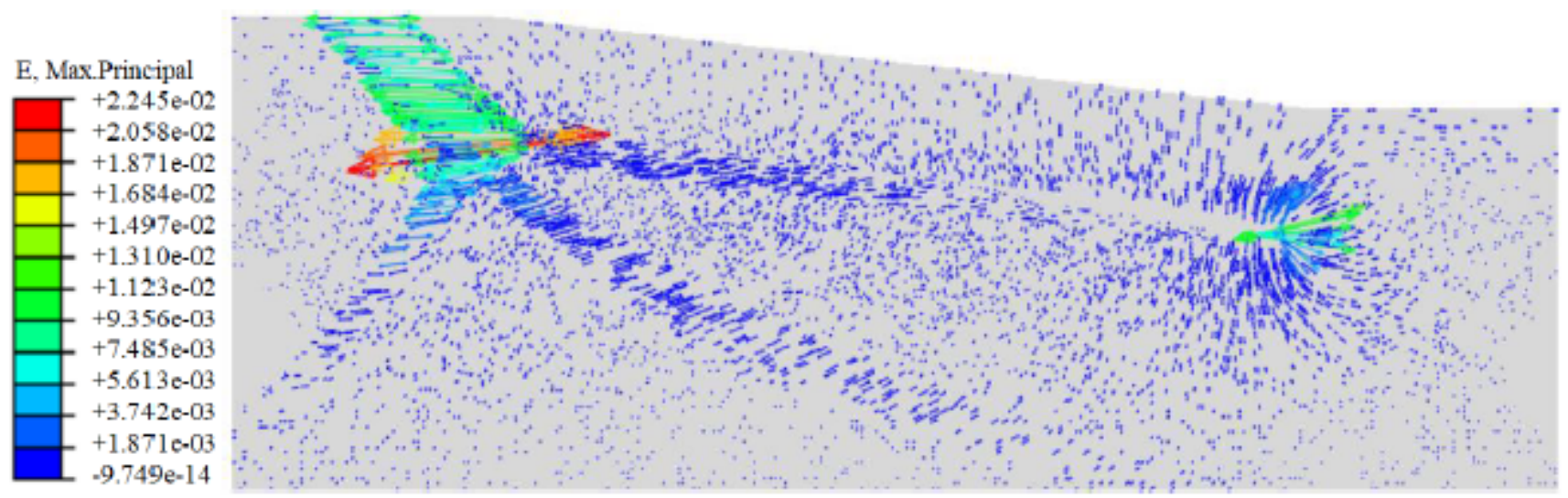

(b) Distribution of true principal strain

\section{Figure 7}

Distribution of strain with degree of decomposition (50\%) 


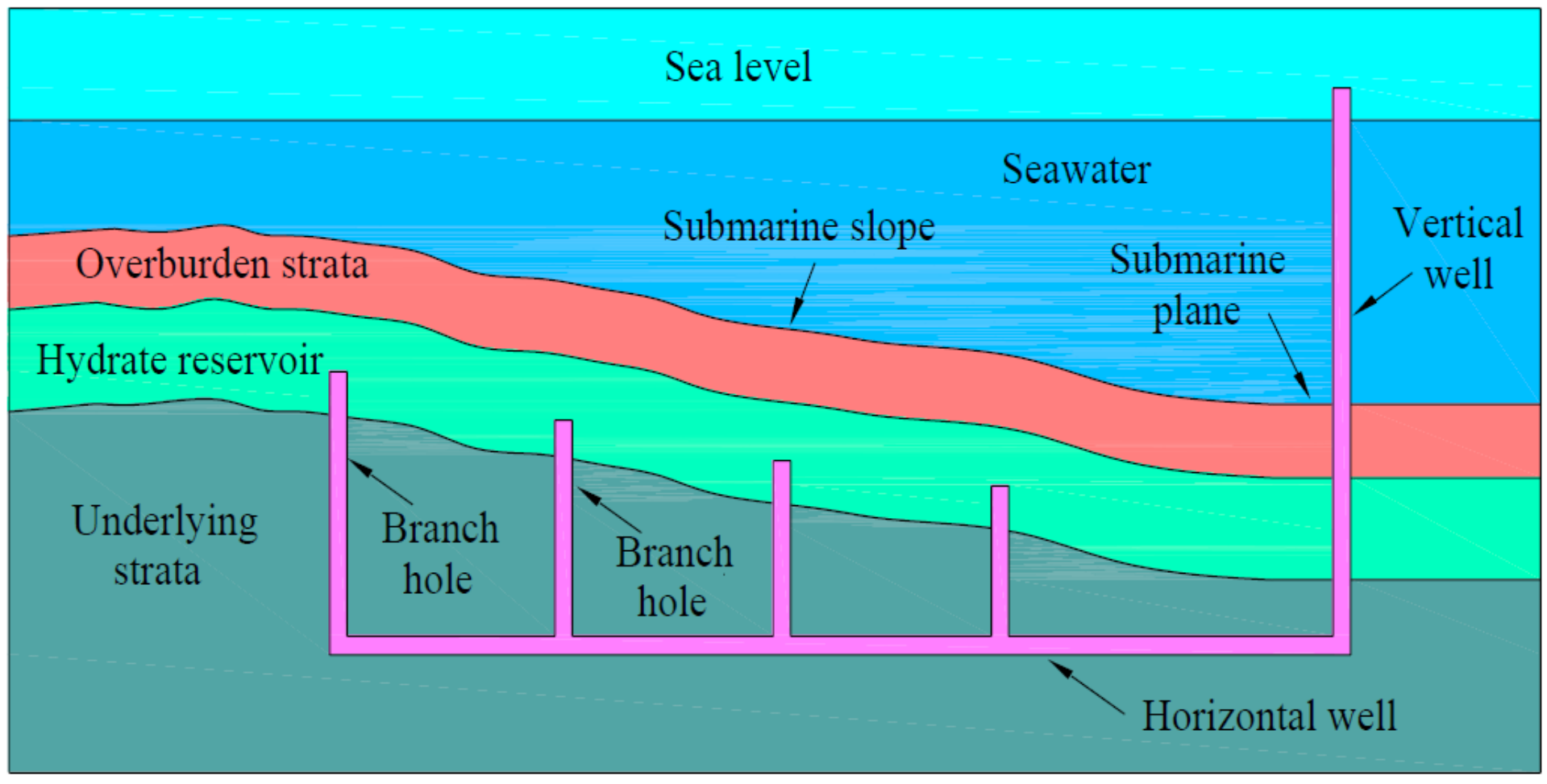

\section{Figure 8}

Schematic diagram of a multi-well joint operation. 


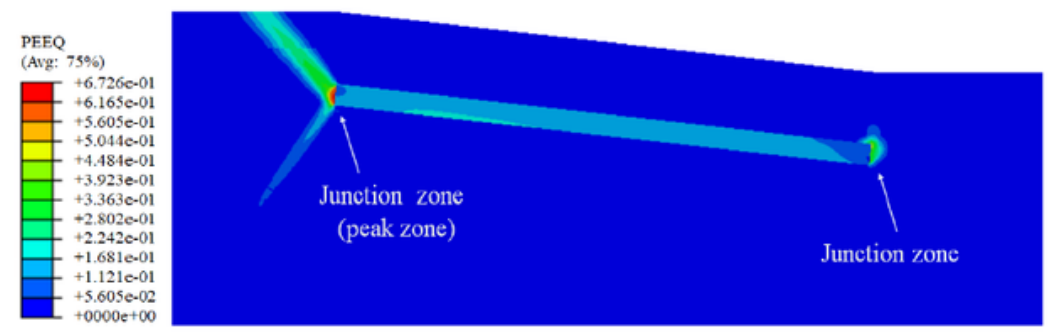

(a) $F_{\mathrm{r}}=1$

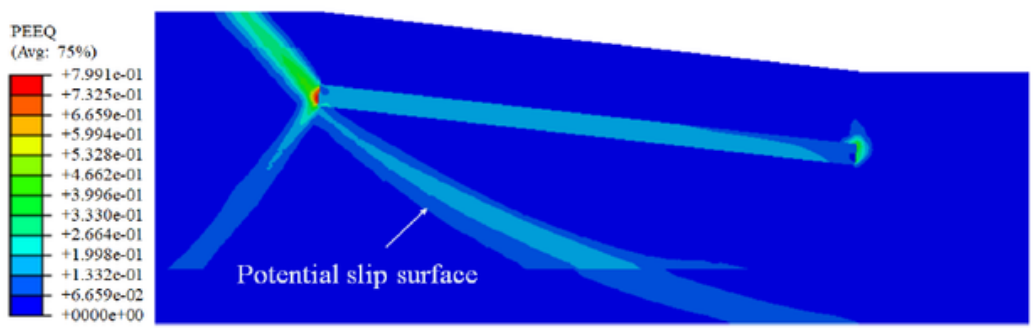

(b) $F_{\mathrm{r}}=1.172$

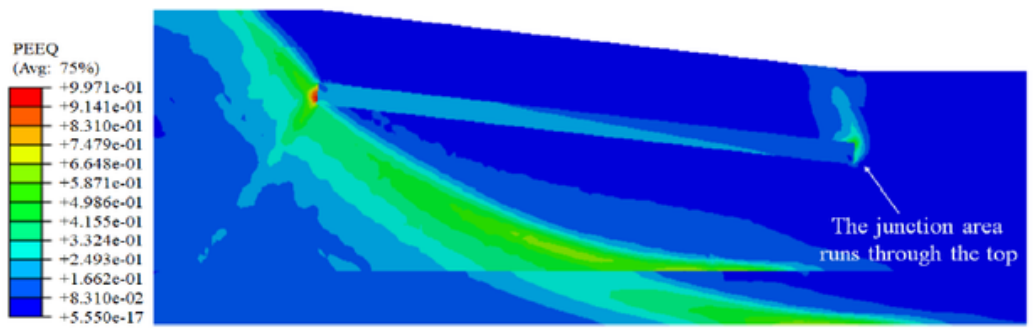

(c) $F_{\mathrm{r}}=1.653$

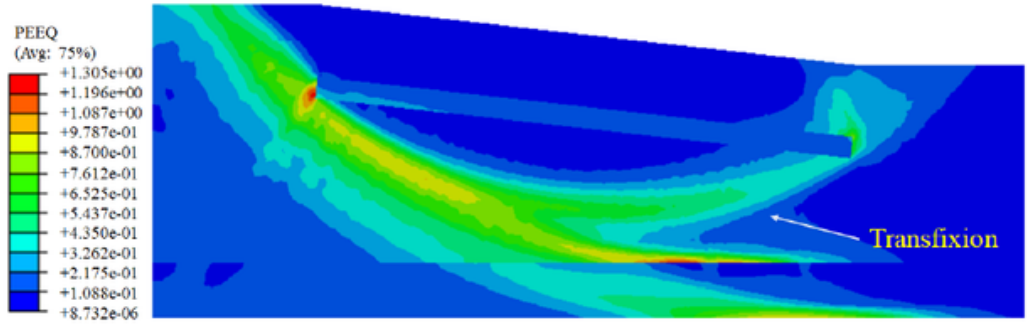

(d) $F_{\mathrm{r}}=1.864$

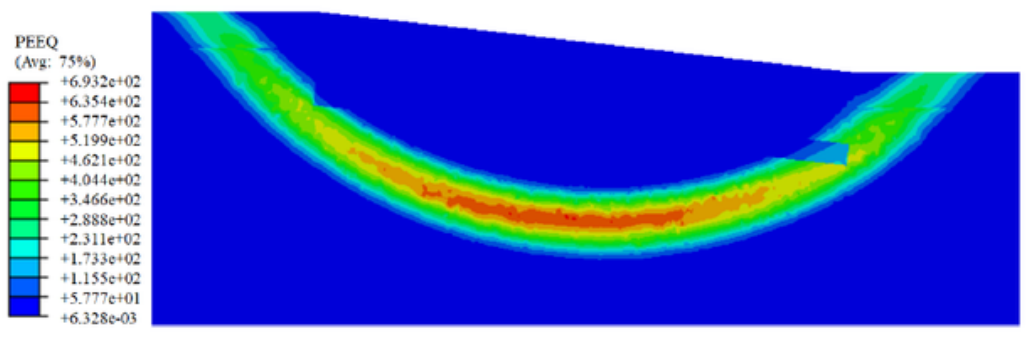

(e) $F_{\mathrm{r}}=1.875$ (end of calculation)

\section{Figure 9}

Landslide process on a submarine slope (decomposition by $75 \%$ ). 


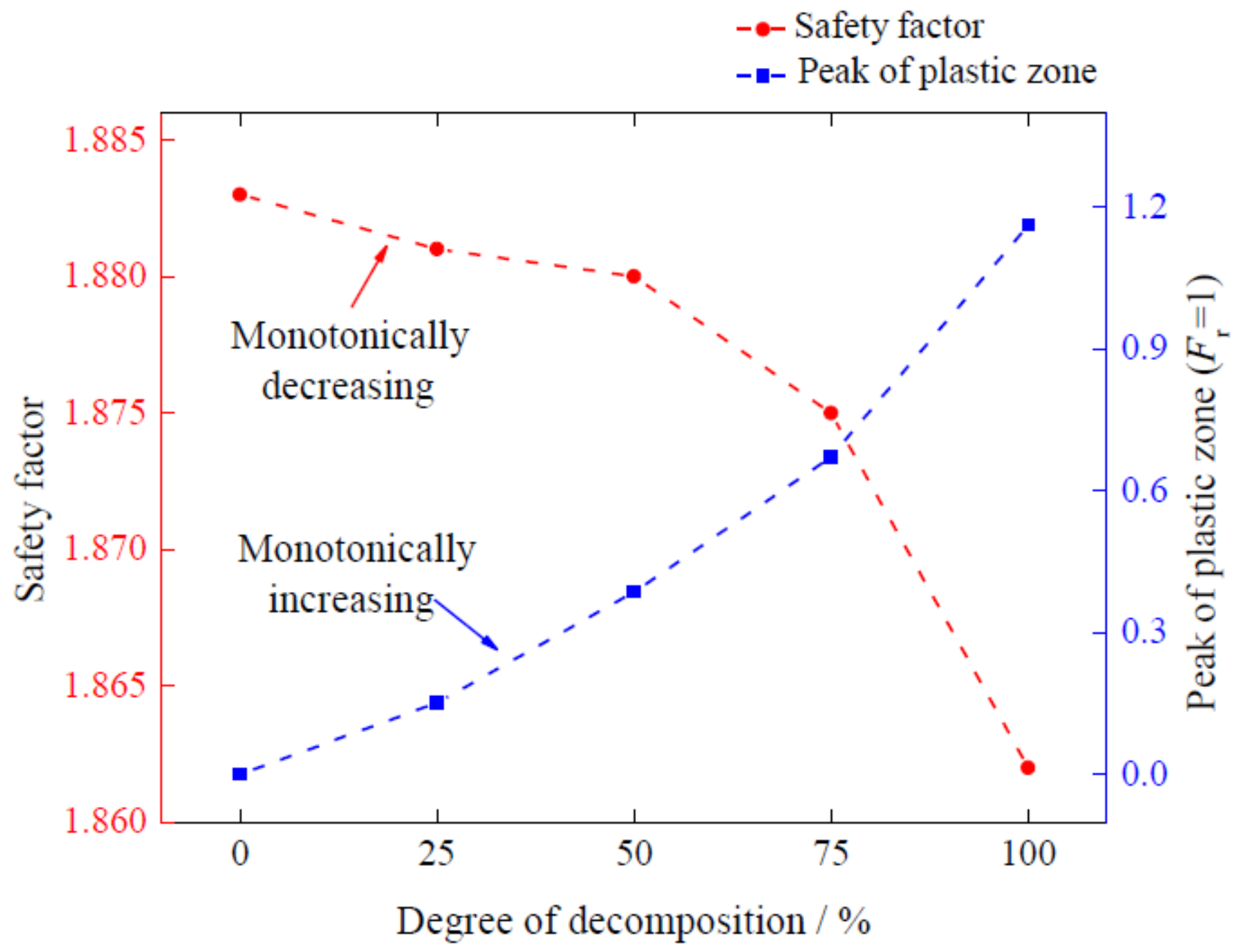

Figure 10

Variation curve of safety factor and peak value of plastic zone. 
$+2.154 c+01$

$+1.975 \mathrm{e}+01$

$+1.795 \mathrm{e}+01$

$+1.616 \mathrm{e}+01$

$+1.436 \mathrm{e}+01$

$+1.257 \mathrm{e}+01$

$+1.077 \mathrm{e}+01$

$+8.977 \mathrm{e}+00$

$+7.182 \mathrm{e}+00$

$+5.386 \mathrm{e}+00$

$+3.591 \mathrm{c}+00$

$+1.795 \mathrm{e}+00$

$+0.000 \mathrm{e}+00$

(a) $F_{\mathrm{r}}=1.851$

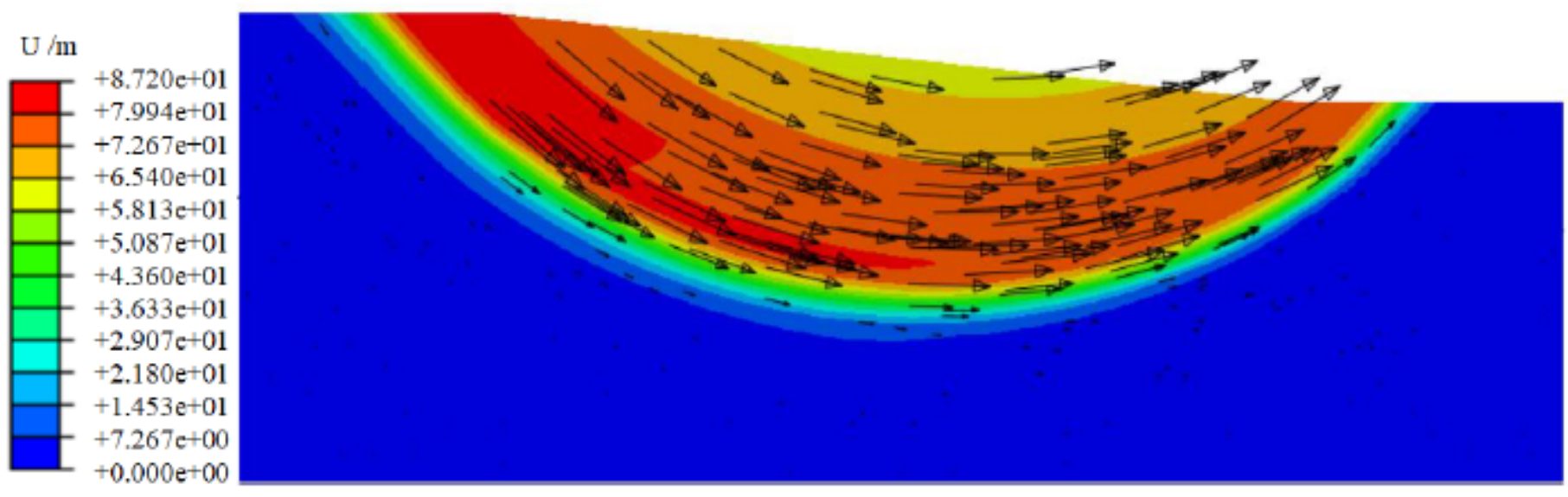

(b) $F_{\mathrm{r}}=1.852$

\section{Figure 11}

Distribution of displacement and vector arrows (decomposition by $100 \%$ ). 